\title{
How Well Do Computerised Decision Support Systems Cover Nursing Standards of Practice? A Literature Review
}

\author{
Saba AKBAR, David LYELL and Farah MAGRABI \\ Centre for Health Informatics, Australian Institute of Health Innovation, Faculty of \\ Medicine, Health and Human Sciences, Macquarie University, Australia
}

\begin{abstract}
The use of computerized decision support systems (DSS) in nursing practice is increasing. However, research about who uses DSS, where are they implemented, and how they are linked with standards of nursing is limited. This paper presents evidence on users and settings of DSS implementation, along with specific nursing standards of practice that are facilitated by such DSS. We searched six bibliographic databases using relevant terms and identified 28 studies, each evaluating a unique DSS. Of these, 24 were used by registered nurses and 19 were implemented in short-term care units. Most of the DSS were found to facilitate nursing standards of assessment and intervention, however, outcome identification and evaluation were the least included standards. These findings not only highlight gaps in systems but also offer opportunities for further research development in this area.
\end{abstract}

Keywords. Computer assisted decision making, nurses' scope of practice, clinical informatics

\section{Introduction}

Decision support systems (DSS) are tools that help clinicians make informed decisions based on existing knowledge and individual patient characteristics. For nurses, such tools can facilitate the dynamic and complex decisions that they make regularly. Nursing is driven by certain standards of practice. The most widely recognised and implemented framework includes six standards of practice: assessment, diagnosis, outcomes identification, planning, implementation, and evaluation. The implementation standard includes four elements: coordination of care, health teaching and health promotion, consultation, and prescriptive authority and treatment [1]. These elements can be unique to users and nursing tasks. Previous reviews have mainly looked at specific nursing tasks performed by DSS such as nursing documentation and medication administration [2]. While DSS have been found to be effective in reducing medication errors and implementing evidence-based practice [3], their roles in supporting nursing standards is understudied. We undertook a systematic review of electronic DSS in nursing. The results of that review have been reported in a separate publication [4]. Here we specifically focus on mapping DSS functions to standards of nursing practice. 


\section{Method}

We searched bibliographic databases including PubMed, CINAHL, Cochrane, Embase, Scopus, and Web of Science using variations of the following terms: decision support, nursing, patient outcomes, care delivery, and decision making. Studies published from Jan 2014 to Mar 2020, and those that evaluated electronic DSS used solely by nurses were included. After the initial search, duplicate entries were removed, and titles and abstracts were screened by two independent reviewers. Non-English articles and conference abstracts were excluded. Full length articles were assessed independently against inclusion criteria by two reviewers. Disagreements were resolved by consensus. Interrater agreement was moderate (Cohen's k 0.565, $\mathrm{n}=69$ ) [5].

\subsection{Data Extraction and Synthesis}

For each included study, descriptive information about study design, DSS users, setting, and nursing standards of practice were extracted. We categorised users into registered nurses, midwives and nurse practitioners [6], and settings into acute care and long term care facilities [7]. We then mapped functions of each DSS to one or more standards of nursing practice.

\section{Results}

The database search retrieved a total of 1,019 articles. Twenty-eight papers, each evaluating a unique DSS, met the inclusion criteria. Eighteen studies were quasiexperimental [8-25], six were randomized controlled trial [26-31], three were descriptive [32-34], and there was one observational study [35].

\subsection{Settings and Users}

The majority of DSS were aimed at registered nurses $(n=24)$ in a variety of clinical settings. The remaining were for nurse practitioners $(n=3)$, or both nurses and midwives $(n=1)$. Nineteen DSS were for short-term care units, including outpatient clinics, ambulance, emergency or urgent care, medical and surgical inpatient units, and critical care areas. Eight were for long term facilities such as nursing homes, community centers, and home healthcare. Only one DSS covered both kinds of settings.

\subsection{DSS Coverage of Nursing Standards of Practice}

As shown in Table 1, the majority of DSS ( $\mathrm{n}=24,86 \%$ ), supported the nursing standard of intervention, followed by assessment $(n=23,82 \%)$. The least commonly supported standards were outcome identification and evaluation. Examples of DSS functions that support nursing standards of practice are given in Figure 1. Within implementation, 18 DSS supported coordination of care; eight supported teaching and promotion; seven prescription and treatment; and three supported the practice of consultation. 
Table 1. Functions of computerized DSS by nursing standards of practice $(n=28)$.

\begin{tabular}{|c|c|c|c|c|c|c|c|}
\hline \multirow[t]{2}{*}{ First author, year } & \multirow[t]{2}{*}{ Setting } & \multicolumn{6}{|c|}{ Nursing standards of practice* } \\
\hline & & $\mathbf{A}$ & $\mathbf{D}$ & $\mathbf{O}$ & $\mathbf{P}$ & I & $\mathbf{E}$ \\
\hline \multicolumn{8}{|c|}{ User group: Registered Nurses } \\
\hline McLead, 2020 [20] & Urgent/emergent care & Yes & Yes & & Yes & Yes & \\
\hline Wouters, 2019 [34] & Urgent/emergent care & Yes & Yes & & Yes & Yes & \\
\hline Tang, 2019 [23] & Nursing homes & Yes & & & Yes & Yes & \\
\hline Reynolds, 2019 [22] & ICU & & & & & Yes & \\
\hline Telford, 2018 [35] & ICU & & & & & Yes & Yes \\
\hline $\begin{array}{l}\text { Mahabee-Gittens, } \\
2018 \text { [19] }\end{array}$ & Urgent/emergent care & Yes & Yes & & \multicolumn{3}{|c|}{ Yes } \\
\hline $\begin{array}{l}\text { Dehgani-Soufi, } 2018 \\
{[13]}\end{array}$ & Urgent/emergent care & Yes & & & Yes & \multicolumn{2}{|l|}{ Yes } \\
\hline Chunmei, 2018 [12] & Hospital inpatient & & Yes & & Yes & \multicolumn{2}{|l|}{ Yes } \\
\hline $\begin{array}{l}\text { Thoma-Lurken, } 2018 \\
\text { [31] }\end{array}$ & Community - Geriatrics & Yes & Yes & & Yes & & \\
\hline Boltin, $2018[10]$ & Urgent/emergent care & Yes & & & & \multicolumn{2}{|l|}{ Yes } \\
\hline Topaz, 2018 [24] & Home health & Yes & & & & \multicolumn{2}{|l|}{ Yes } \\
\hline Barken, 2017 [32] & Telemedicine & Yes & Yes & & & \multicolumn{2}{|l|}{ Yes } \\
\hline Geurts, 2017 [29] & Urgent/emergent care & Yes & Yes & & Yes & Yes & Yes \\
\hline Kihlgren, 2016 [17] & Urgent/emergent care & Yes & & & & \multicolumn{2}{|l|}{ Yes } \\
\hline Bennett, 2016 [9] & Urgent/emergent care & Yes & Yes & & Yes & \multicolumn{2}{|l|}{ Yes } \\
\hline Ajay, $2016[8]$ & Community health centers & Yes & Yes & & Yes & Yes & Yes \\
\hline Febretti, 2016 [14] & Community-Palliative care & Yes & Yes & & & \multicolumn{2}{|l|}{ Yes } \\
\hline Cortez, 2016 [27] & Outpatient clinics & & & & Yes & \multicolumn{2}{|l|}{ Yes } \\
\hline McDonald, 2016 [30] & Home health & Yes & Yes & & & \multicolumn{2}{|l|}{ Yes } \\
\hline Lytle, 2015 [18] & Hospital inpatient & Yes & Yes & & Yes & \multicolumn{2}{|l|}{ Yes } \\
\hline Dallaire, 2015 [28] & Ambulance & Yes & & & & \multicolumn{2}{|l|}{ Yes } \\
\hline Bowles, 2015 [11] & Hospital inpatient & Yes & Yes & & Yes & \multicolumn{2}{|l|}{ Yes } \\
\hline $\begin{array}{l}\text { Ciqueto-Peres, } 2015 \\
\text { [33] }\end{array}$ & Hospital inpatient & Yes & Yes & Yes & Yes & & \\
\hline Olsho, 2014 [21] & Nursing homes & & Yes & & Yes & & \\
\hline \multicolumn{8}{|c|}{ User group: Nurse Practitioners } \\
\hline Harless, 2016 [15] & Outpatient clinics & Yes & Yes & & Yes & \multicolumn{2}{|l|}{ Yes } \\
\hline Vetter, $2015[25]$ & Home health & Yes & Yes & & & & \\
\hline Bakken, 2014 [26] & Various specialties & Yes & Yes & Yes & Yes & \multicolumn{2}{|l|}{ Yes } \\
\hline \multicolumn{8}{|c|}{$\begin{array}{c}\text { User group: Registered Nurses and } \\
\text { Midwives }\end{array}$} \\
\hline Horner, 2014 [16] & Outpatient clinics & Yes & Yes & & Yes & \multicolumn{2}{|l|}{ Yes } \\
\hline Percentage & studies $(\mathbf{n}=\mathbf{2 8}) * *$ & $82 \%$ & $68 \%$ & $7 \%$ & $61 \%$ & $86 \%$ & $11 \%$ \\
\hline
\end{tabular}

*A-assessment, $\mathrm{D}=$ diagnosis, $\mathrm{O}=$ outcomes identification, $\mathrm{P}=$ planning, $\mathrm{I}=$ implementation, $\mathrm{E}=$ evaluation.

**Categories are not mutually exclusive, DSS could be mapped to multiple standards.

\section{Discussion}

Our review summarises recent evidence on nursing DSS with an aim to establish connections between DSS functions and nursing standards of practice. We found that the application of DSS is widespread, covering all areas of patient-nurse interactions within the healthcare continuum. However, current DSS tend to focus on a sub-set of clinical problems and perform limited clinical tasks like triage recommendations for urgent or emergent care needs; medication dose recommendation reminders to complete assessments; or risk score calculation (Figure 1). Moreover, these DSS do not sufficiently 
cover all clinical settings. For instance, only four DSS in our review were applicable to hospital inpatient areas, which employs the highest number of nurses and collects a large amount of health-related data [36].

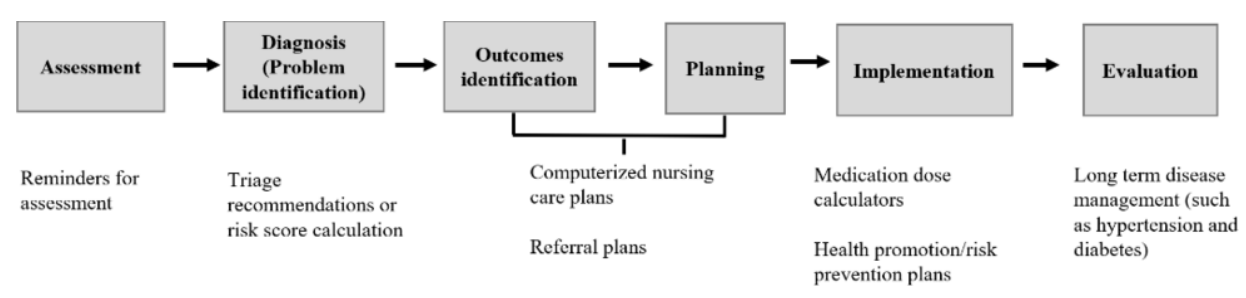

Figure 1. Examples of specific DSS functions linked with standards of nursing practice.

While most DSS support multiple nursing functions, the focus on outcome identification and evaluation is minimal. Majority of the DSS facilitate assessment function by a pre- designed series of questions to ensure all relevant information is collected. These systems then generate recommendations about what a nurse should do (implementation), without clearly explaining what the nurses should expect to see as an outcome. This missing piece of information is directly linked with evaluation of efficacy of these actions. Adding components about expected outcomes and evaluation can enhance clinical judgement and uptake of DSS by nurses [37].

\section{Conclusion}

Computerised DSS can facilitate multiple standards of nursing practice, including assessment, diagnosis, outcomes identification, planning, implementation and evaluation. However, their scope is limited in setting and functions. More research is needed to understand how expanding their scope, especially including components of outcomes identification and evaluation, and combining standards of practice within DSS can affect nurses' decision making, and patient outcomes.

\section{References}

[1] ANA. Nursing: Scope and Standards of Practice. 3rd ed. Silver Springs, MD: ANA; 2015.

[2] Jia P et al. The effects of clinical decision support systems on medication safety: An overview. PLoS One. 2016;11(12):e0167683.

[3] Coiera E. Guide to health informatics. Third edition. ed. Ebooks C, editor: Boca Raton : CRC Press, Taylor \& Francis Group; 2015.

[4] Akbar S et al. Automation in nursing decision support systems: A systematic review of effects on decision-making, care delivery and patient outcomes. JAMIA. 2021; In Press.

[5] Landis JR et al. The measurement of observer agreement for categorical data. Biometrics. 1977;33(1):159-74.

[6] NMBA. Professional Standards 2017 [Available from: https:/www.nursingmidwiferyboard.gov.au/ Codes-Guidelines-Statements/Professional-standards.aspx

[7] Hirshon JM et al. Health systems and services: The role of acute care. Bulletin of the World Health Organization. 2013;91:386-8.

[8] Ajay VS et al. Development of a smartphone-enabled hypertension and diabetes mellitus management package to facilitate evidence-based care delivery in primary healthcare facilities in India: The mPower Heart Project. J Am Heart Assoc. 2016;5(12). 
[9] Bennett $P$ et al. A quantitative study investigating the effects of computerised clinical decision support in the Emergency Department. 2016;225:53-7.

[10] Boltin N et al. Mobile decision support tool for emergency departments and mass casualty incidents (EDIT): Initial Study. JMIR Mhealth Uhealth. 2018;6(6):e10727.

[11] Bowles KH et al. Successful electronic implementation of discharge referral decision support has a positive impact on 30- and 60-day readmissions. Res Nurs Health. 2015;38(2):102-14.

[12] Chunmei R et al. Design and application of nursing CDSS based on structured EMR. Stud Health Technol Inform. 2018;250:238-9.

[13] Dehghani Soufi $M$ et al. Decision support system for triage management: A hybrid approach using rulebased reasoning and fuzzy logic. Int J Med Inform. 2018;114:35-44.

[14] Febretti A et al. Evaluating a clinical decision support interface for end-of-life nurse care. 2014:1633-8.

[15] Harless DF. The impact of computer decision support software by nurse practitioners on functional outcomes for patients with acute lower back pain a DNP project. Impact of Computer Decision Support Software by Nurse Practitioners on Functional Outcomes for Patients with Acute Lower Back Pain a DNP Project. 2016:1-.

[16] Horner V et al. Evaluation of a guidelines-based e-health decision support system for primary health care in South Africa. 2014;28-September-2014:142-7.

[17] Kihlgren A et al. A Decision Support System (DSS) for municipal nurses encountering health deterioration among older people. BMC Nurs. 2016;15:63.

[18] Lytle KS et al. Clinical decision support for nurses: A fall risk and prevention example. Comput Inform Nurs. 2015;33(12):530-7; quiz E1.

[19] Mahabee-Gittens EM et al. An electronic health record-based strategy to address child tobacco smoke exposure. Am J Prev Med. 2018;54(1):64-71.

[20] McLeod SL et al. Interrater reliability, accuracy, and triage time pre- and post-implementation of a realtime electronic triage decision-support tool. Ann Emerg Med. 2020;75(4):524-31.

[21] Olsho LEW et al. Evaluation of AHRQ's on-time pressure ulcer prevention program: A facilitatorassisted clinical decision support intervention for nursing homes. Med Care. 2014;52(3):258-66.

[22] Reynolds TL et al. Evaluating a handheld decision support device in pediatric intensive care settings. JAMIA Open. 2019;2(1):49-61.

[23] Tang V et al. An adaptive clinical decision support system for serving the elderly with chronic diseases in healthcare industry. Expert Systems. 2019;36(2).

[24] Topaz M et al. Improving patient prioritization during hospital-homecare transition: A pilot study of a clinical decision support tool. Res Nurs Health. 2018;41(5):440-7.

[25] Vetter MJ. The influence of clinical decision support on diagnostic accuracy in nurse practitioners. Worldviews Evid Based Nurs. 2015;12(6):355-63.

[26] Bakken $\mathrm{S}$ et al. The effect of a mobile health decision support system on diagnosis and management of obesity, tobacco use, and depression in adults and children. Journal for Nurse Practitioners. 2014;10(10):774-80.

[27] Cortez S et al. Measuring clinical decision support influence on oncology nursing practice. Oncology Nursing Forum. 2015;42(2):E245-E.

[28] Dallaire C et al. Prehospital decision system supports appropriate transfer of older adults direct to a community-based hospital. Evidence-based nursing. 2015;18(4):127-.

[29] Geurts D et al. Implementation of clinical decision support in young children with acute gastroenteritis: a randomized controlled trial at the emergency department. Eur J Pediatr. 2017;176(2):173-81.

[30] McDonald MV et al. Outcomes of clinical decision support (CDS) and correlates of CDS use for home care patients with high medication regimen complexity: A randomized trial. J Eval Clin Pract. 2016;22(1):10-9.

[31] Thoma-Lurken $T$ et al. Evaluation of a decision support app for nurses and case managers to facilitate aging in place of people with dementia. A randomized controlled laboratory experiment. Geriatric nursing (New York, NY). 2018;39(6):653-62.

[32] Barken TL et al. Advancing beyond the system: telemedicine nurses' clinical reasoning using a computerised decision support system for patients with COPD - an ethnographic study. BMC Med Inform Decis Mak. 2017;17(1):181.

[33] Ciqueto Peres HH et al. Usability testing of PROCEnf-USP: A Clinical Decision Support system. Stud Health Technol Inform. 2015;216:247-50.

[34] Wouters LT et al. Tinkering and overruling the computer decision support system: Working strategies of telephone triage nurses who assess the urgency of callers suspected of having an acute cardiac event. J Clin Nurs. 2020;29(7-8):1175-86.

[35] Telford ED et al. A Bedside Computerized Decision-Support Too for Intravenous Insulin Infusion Management in Critically Ill Patients. Joint Commission Journal on Quality and Patient Safety. 2018;44(5):299-303. 
[36] NIH. Health Data Sources: U.S. National library of medicince; 2018 [

[37] Ahamed T et al. Towards a Methodology for Nursing-Specific Clinical Decision Support Systems (CDSS). Journal of Decision Systems. 2016;25(sup1):23-34. 